\title{
OS MEIOS AMBIENTES DA HISTÓRIA AMBIENTAL BRASILEIRA: PELA ABERTURA DA CAIXA-PRETA
}

THE ENVIRONMENTS OF BRAZILIAN ENVIRONMENTAL HISTORY: FOR THE OPENING OF THE BLACK BOX

Roger Domenech Colacios* rdcolacios@gmail.com

RESUMO: Este artigo tem como proposta analisar o conceito de meio ambiente utilizado pela historiografia ambiental brasileira. A discussão é feita sobre as várias modalidades que o meio ambiente adquire frente a três matrizes teóricas que guiam os estudos históricos no Brasil: ecológica, socioambiental e geográfica. A metodologia está assentada no instrumental Latouriano, utilizado pela História das Ciências, referente às caixas-pretas conceituais. A perspectiva do artigo está em auxiliar no debate sobre a polissemia do meio ambiente, seus vários usos e contribuir para uma melhor conformação entre objetos, teorias e métodos de trabalho no campo de pesquisa da História Ambiental brasileira.

PALAVRAS-CHAVE: História Ambiental, Caixa-preta, Brasil.

ABSTRACT: This article aims to analyze the concept of the environment used by the Brazilian environmental historiography. It discusses the various modalities that the term environment acquires in three matrices of historical studies that guide the research in environmental history in Brazil: the ecological, the socio-environmental, and the geographical matrix. The methodology is based on Bruno Latour's instruments used in the History of Sciences regarding conceptual black boxes. The proposal intends to help in the debate on the polysemy of the term environment and its various uses, and contribute to the better conformation between objects, theories and working methods in the field of Environmental History research.

KEYWORDS: Environmental History, Black Box, Brazil.

A História Ambiental é uma área de pesquisas na qual, desde a década de 1970 nos EUA e final dos anos 1980 no Brasil, pesquisadores de diversas origens disciplinares vêm desenvolvendo investigações. Apesar disso, é ainda um campo de estudos incipiente no meio historiográfico. $\mathrm{O}$ volume de pesquisas no Brasil certamente aumentou nos últimos anos. $\mathrm{A}$ área ganhou espaço na Associação Nacional de História do Brasil (ANPUH) e organizou-se em grupos de trabalho (GTs) tanto nos estados como nacionalmente. Eventos de porte internacional surgiram e tornaram-se parte da agenda dos pesquisadores nacionais e estrangeiros. Em algumas universidades brasileiras, a História Ambiental entrou na grade curricular; em muitos programas de pós-graduação, dissertações e teses foram defendidas e laboratórios foram criados visando à nucleação de pesquisas na área.

Esse fortalecimento institucional da História Ambiental no Brasil, porém, não está sendo acompanhado por uma discussão teórica e metodológica. Poucos são os pesquisadores que, nos últimos anos, se dedicaram a trazer luzes ou então fazer novas propostas que pudessem orientar o campo de estudo nos desafios epistemológicos que enfrenta. A

\footnotetext{
* Pós-doutorando pelo Departamento de História da UNESP/Assis. Doutor em História Social pelo FFLCH/USP. 
perspectiva multidisciplinar, por exemplo, é uma ferramenta muito presente nos estudos, mas pouco discutida entre os pesquisadores. O trabalho com uma variedade de disciplinas, tanto das ciências humanas quanto das biológicas e físicas, amplia ainda mais as possibilidades metodológicas, inserindo conceitos que não faziam parte do escopo historiográfico. Entropia, ecossistemas, biodiversidade, entre outros, passaram a compor a linguagem do pesquisador. Tal enriquecimento do vocabulário conceitual abriu as portas para novas fontes históricas, auxiliando inclusive estudos em outras áreas da historiografia. Em contraponto a esta ampliação dos horizontes conceituais, a crítica de seus usos não vem sendo uma prática comum entre os historiadores ambientais ${ }^{1}$.

O reconhecimento e a devida atenção aos significados dos conceitos utilizados representam o encaixe exato deles na análise histórica proposta. Já o uso errado, distorcido, pode levar à confusão e ao desentendimento entre os pesquisadores e seus objetos e entre estes e os futuros leitores de seus trabalhos. Apesar de esta ser uma equação óbvia, essa preocupação tem passado ao largo das pesquisas publicadas, das teses defendidas e das discussões entre os historiadores ambientais. A consequência desta situação é a caracterização dos conceitos empregados na área como espécies de "caixas-pretas". Estas caixas encerram em seu interior os significados que os pesquisadores pretendem dar a elas e não mais são abertas para visualizar seu conteúdo, seja para discutir ou reformular.

Este artigo pretende discutir o uso pelos historiadores de um conceito fundamental: o meio ambiente. Meio Ambiente, mesmo sendo a principal referência do vocabulário deste campo historiográfico, não é discutido pelos pesquisadores. Caracteriza-se como uma verdadeira "caixa-preta" utilizada em larga escala. É possível observar, no entanto, finalidades diversas e, consequentemente, significados diferentes em cada pesquisa ou grupos de historiadores. Essa variação do que é meio ambiente para a História Ambiental está condicionada a determinadas matrizes que orientam a pesquisa e à leitura que o pesquisador tem de seu objeto de estudo. A intenção neste texto é a de identificar algumas destas matrizes, aquelas consideradas aqui as principais, e tentar iniciar a abertura da "caixa-preta" meio ambiente. São elas: matriz ecológica, matriz socioambiental e a matriz geográfica.

\footnotetext{
${ }^{1}$ Deve-se ressaltar que, em texto recente, o professor Jozimar Paes de Almeida, da Universidade Estadual de Londrina (UEL), que desde a década de 1980 vem trabalhando com a História Ambiental no Brasil, discutiu o uso de alguns destes conceitos, especialmente oriundos da física (ALMEIDA, 2011).
} 
O artigo inicialmente apresenta uma reflexão geral sobre a noção de "caixa-preta", depois aborda os diversos significados de meio ambiente para outras áreas do conhecimento, como a geografia, biologia e a filosofia. Na sequência discute as características das três matrizes propostas e utiliza como exemplos as obras de pesquisadores nacionais e alguns estrangeiros que têm influência na historiografia do meio ambiente brasileira.

\section{Discutindo as "caixas-pretas"}

O termo caixa-preta é comumente relacionado aos trabalhos de Bruno Latour e também encontram base na Social Construction of Technology (SCOT) em artigos e livros publicados durante a década de 1980 por Trevor Pinch e Wiebe Biejker. Autores que têm nas Science Studies seu campo de atuação, com as discussões centradas em questões epistemológicas, controvérsias nos enunciados e os processos de construção da tecnologia, conforme apontam Pinch e Biejker (1984) e Latour (2000). A noção de caixa-preta foi tomada emprestada pela Science Studies da cibernética. Formulada por Wilhem Cauer em 1945, determina em um circuito eletrônico uma peça ou sistema de alta complexidade, cuja representação gráfica é difícil ou mesmo impossível, conforme explicou Latour (2000, p. 14): “A expressão caixa-preta é usada... sempre que uma máquina ou um conjunto de comandos se revela complexo demais"; diante disso é "desenhada uma caixinha preta, a respeito da qual não é preciso saber nada, senão que o que nela entra e o que dela sai”. O significado da caixapreta para a esquematização da máquina ou do sistema representado está em seus inputs e outputs. A informação que entra e a forma como sai da caixa é o determinante do valor da peça para todo o componente. Por exemplo, na composição gráfica da denominada "placamãe" de um computador, seus transistores, capacitores, fusíveis e afins, são representados graficamente, porém, os diagramas internos de cada um não faz parte da representação. Ocorre o mesmo com os microchips e processadores. A questão principal colocada para as caixas-pretas é a seguinte: funciona quando bem posicionada em meio ao circuito eletrônico? Se sim, cumpriu sua função, caso não, deve ser reavaliado o projeto, pois a peça, quando não apresenta defeito, deve funcionar.

Deve-se atribuir esse conceito a um modelo de estudos das ciências. De caráter construtivista, os trabalhos que utilizam a noção de caixas-pretas preveem a análise das ciências enquanto um processo de fabricação do conhecimento. Os enunciados, neste modelo, seriam constituídos em etapas que invariavelmente estão permeadas de 
controvérsias. Disputas em torno da veracidade e da aceitação social do fato científico contribuem tanto para movimentar os estudos e argumentações quanto para impedir o avanço de determinados grupos científicos em torno da concretização do enunciado. Este modelo "construtivista", de que Latour, Pinch e Biejker podem ser listados como representantes, entende as caixas-pretas como elementos que, embora prenhes de controvérsias e demais implicações das redes científicas, servem ao propósito dos cientistas de o encaixarem em seus esquemas e equipamentos; tudo depende do input e output que a caixa proporciona.

Nas ciências humanas e sociais, as caixas-pretas podem ser traduzidas como aqueles conceitos que são utilizados por muitos pesquisadores sem que, no entanto, haja a preocupação com a seu significado. No caso, é possível observar as caixas-pretas sendo de dois tipos: o primeiro ocorre quando o autor emprega o conceito de forma exata (input), obtendo um entendimento correto por seus leitores (output), portanto, havendo a consonância entre entrada da informação e saída dela. O segundo tipo ocorre quando os conceitos são inseridos em frases e argumentos (input) sem que os entendimentos corretos de seus significados sejam apreendidos pelo autor; invariavelmente isto acaba provocando a distorção de seus sentidos originais, que são transformados para atender à disposição da frase ou da intenção do autor (output), nesta situação cabe ao leitor aceitar a utilização do conceito, caso ele tenha tido um contato anterior com ele, ou então questionar o uso pelo autor, o que pode comprometer o restante do argumento.

Os historiadores das ciências, por exemplo, utilizam esse procedimento em boa medida em seus trabalhos. Quando se detêm diante de um enunciado científico comumente associado ao chamado "núcleo duro" das ciências, eles podem o considerar uma caixa-preta, seguir utilizando-o sem se preocupar com o conteúdo, seu significado e as controvérsias envolvidas na determinação dele ou, então, podem desconstruir essa caixa-preta, procurando interpretar os processos científicos e sociais inerentes à construção do enunciado. Assim, enunciados e conceitos científicos tais como "mudanças climáticas", "entropia", "doenças" ou mesmo os meandros tecnológicos e afins invariavelmente são desconstruídos de forma a levar à reflexão de seus significados e processos de fabricação.

\section{Os meios ambientes nas outras ciências}


É certo que meio ambiente é um conceito polissêmico. Sua definição pode ser encontrada em várias especialidades científicas. Pela geografia, Holzer afirma que o termo meio ambiente tem sentido original amplo, "uma relação dialética com a palavra 'mundo', assim como com o termo 'paisagem"' (HOLZER, 1997, p. 81). Holzer traz também outras duas definições contemporâneas da geografia, de Rapoport e de Tuan. Para o primeiro, ambiente seria definido como "qualquer condição ou influência situada fora do organismo, grupo ou sistema que se estuda" (RAPOPORT citado por HOLZER 1997, p. 80) e, para o Tuan, "As condições sob as quais qualquer pessoa ou coisa vive ou se desenvolve; a soma total de influências que modificam ou determinam o desenvolvimento da vida ou do caráter" (TUAN citado por HOLZER, 1997, p. 80). Na geografia brasileira, ao termo ambiente foi acrescentado o conceito de "meio", ampliando, explica Holzer, a escala de análise, mesmo que ainda assim restrinja seu sentido, mantendo o ser humano como um "mero espectador" (HOLZER, 1997, p. 81).

Outros geógrafos apresentam noções diferentes de meio ambiente das apresentadas por Holzer. Relacionado a certo estado de consciência, Luiz D’Agostini remete o termo a uma condição psicológica, não necessariamente vinculada a um lugar concreto, um espaço empírico, mas "Ambiente é muito mais produto de interessantes estados de consciência em um lugar, do que um lugar interessante que alguns pressupostos mais conscientes gostariam de manter em certo estado" (D’AGOSTINI, 2002, p. 148). Haveria a necessidade de uma distinção entre o meio e o ambiente, embora isto não signifique que perderiam seu sentido em conjunto. Meio remeteria a componentes concretos enquanto ambiente, a significantes relacionais abstratos. Assim, nem sempre onde é estabelecido um "meio" este possa ser somado a um “ambiente” (D’AGOSTINI, 2002).

Os geógrafos Wagner Costa Ribeiro e de Manoel Carlos de Oliveira apresentam outras definições de meio ambiente. Analisado a partir de duas matrizes, o meio ambiente, para Wagner Ribeiro (1991, p. 29), poderia ser dividido entre ambiente natural e produzido. Uma divisão teórica que não elimina a justaposição entre ambas as definições, o meio ambiente seria uma "síntese das diversas formas de apreensão que a organização social dos agrupamentos humanos definiu ao longo de sua trajetória" e que, por fim, acabou por associar o termo à ideia de "natureza". De caráter "científico-tecnológico", essa definição presente na contemporaneidade abarca também um sistema de valores digno de uma sociedade de 
consumo. Muito embora o autor reconheça que existam, na atualidade, visões diferentes desse ambiente como natureza em outros grupos humanos que estariam destacados dessa orientação consumista (RIBEIRO, 1991).

Por sua vez, Oliveira traz o meio ambiente inserido em uma noção de sistema. 0 sistema ambiental, como o autor determinou, permitiria a flexibilidade entre suas características ecológicas e humanas. Associando o meio ambiente, em dependência dos fluxos de energia e elementos dominantes, a ecossistema ou então geossistema:

O sistema ambiental sendo hierarquizado é composto de subsistemas que representam unidades... onde estão expressas as relações de entrada de energia e seu fluxo, como ocorre no sistema global. Quando os arranjos da natureza dominam essas unidades tem-se o ecossistema, quando o homem é o componente dominante de um subsistema, a unidade passa a ser o geossistema (OLIVEIRA, 1982, p. 58).

Essas divergências no entendimento de meio ambiente na Geografia enriquece o vocabulário utilizado pelos especialistas, fornecendo uma variedade de possibilidades interpretativas. Um debate benéfico a esta área de estudos ambientais. A caixa-preta "meio ambiente" está sendo aberta constantemente pelos geógrafos. Isto mostra que, quando suas pesquisas focam em novos objetos, o conceito é debatido, revisto e readequado.

Entre os filósofos é possível indicar também alguns significados de meio ambiente. Bruno Latour, citado aqui anteriormente, apresentou sua preocupação com o sentido dado a meio ambiente na atualidade. Para o filósofo francês e seus dois coautores Cécile Schwartz e Florian Chavolin, a definição é plural, não havendo um meio ambiente no singular, mas vários, qualificando-o como "meios ambientes". A pluralidade do conceito gera duas significações para ele: uma primeira, em que é "complementar de um conjunto" e outra, em que é "união entre o conjunto e seu complemento". O primeiro sentido leva os autores a compreender o meio ambiente como aquilo que "designa tudo o que não nos diz respeito, a infinita reserva ou o depósito infinito de nossas ações", enquanto o segundo sentido "designa tudo que deixou de nos cercar para por-se a nos invadir e nos dizer respeito" (LATOUR et al., 1998, p. 92). Os primeiro e segundo sentidos podem ser complementares, como Latour exemplifica com a camada de ozônio: mesmo estando a milhares de metros acima de nossas cabeças, portanto distante de nós, após o aparecimento dos aerossóis tornou-se parte de nosso meio ambiente, pois apenas o ato de apertar um botão da lata de spray nos coloca em contato direto com esta camada atmosférica. Isto remete, conforme os autores, a que as ciências 
humanas deveriam repensar o conceito de meio ambiente, partindo de uma visão holística e não tão restritiva como ainda ocorre nos meios acadêmicos (LATOUR et al., 1998).

$\mathrm{Na}$ Ecologia, o meio ambiente está atrelado a ecossistema. Eugene Odum definiu que Ecologia era o estudo dos seres vivos e o meio ambiente em que habitam, chegando a definir a área como "biologia do ambiente" (ODUM, 2004, p. 4). Entretanto, no desenrolar da compreensão que faz da área de estudo, determina que o ecossistema é a "totalidade dos organismos de uma determinada área" que interage com o "ambiente físico" (p. 11). Pode ser compreendido, então, que para o ecólogo o ambiente é plasmado ao ecossistema de forma a ser o espaço de atuação dos organismos vivos. Embora, ainda considerando o ambiente como algo externo a estes organismos, Odum entende que ocorre uma interação entre o "ambiente inerte" e os seres vivos (ODUM, 2004).

As definições de Odum, ainda que restritas a uma leitura geral da ecologia em relação ao meio ambiente poderiam ser desmembradas para outras subáreas desta ciência, tais como a ecologia humana e mesmo a ecologia política. No entanto, essas apresentam apenas variações da definição original de Odum, sendo talvez a última, ecologia política, uma distensão mais significativa, ao incorporar a economia, cultura e política das sociedades como elementos da interação entre os seres vivos e o ambiente.

Para a caracterização pretendida aqui, a abertura da caixa-preta "meio ambiente" na História Ambiental, essas definições, ainda que generalizadas e sem a profundidade analítica requerida para a compreensão dos enunciados provenientes de outros ramos científicos, permitem estabelecer um parâmetro e algumas conclusões. O parâmetro é que, apesar de tratar de um leque amplo de definições do conceito de meio ambiente, há uma tendência, em acordo com a afirmação de Wagner Ribeiro (1991), de ser afunilado como sinônimo de "natureza". Portanto, a associação com natureza é o principal parâmetro de compreensão de meio ambiente, sejam pelos vários autores citados, seja também pelo senso comum. As conclusões estão no item seguinte.

\section{Três matrizes da História Ambiental no Brasil}

Os historiadores ambientais não fogem à regra. Natureza é a categoria principal de entendimento do que é meio ambiente para esses pesquisadores. Mesmo que seja possível encontrar outros tratamentos, tais como recursos naturais, ecossistema, biodiversidade, 
paisagem, território etc., de forma geral, a ideia de natureza permanece como o principal guia da historiografia ambiental. A partir da relação estabelecida entre natureza e meio ambiente na História Ambiental, é possível perceber que os pesquisadores interpretam o conceito em escalas e perspectivas diversas. Essa diversidade interpretativa, no entanto, está centrada em três matrizes: ecológica, socioambiental e geográfica².

A primeira matriz, ecológica, é característica da História Ambiental produzida nos Estados Unidos da América (EUA) e serviu de base para grande parte dos estudos nesta área entre os brasileiros. Esta matriz demonstra profunda ligação com os estudos das ciências naturais, particularmente a Biologia e a Ecologia. O conceito de meio ambiente utilizado pelos pesquisadores desta matriz remete à ideia de natureza separada da sociedade. Uma natureza intocada pela civilização. Tal perspectiva é fundamental para a compreensão desta primeira matriz. Arraigada em uma valorização da natureza intocada está toda uma concepção de mundo selvagem em que está solidificado o conceito de meio ambiente. Raiz desta questão é a ideia de wilderness.

O historiador estadunidense Roderick Nash, em um artigo de 1976 para a revista Environmental Review, caracteriza a wilderness como: "Essentially... a state of mind. It is the feeling of being far removed from civilization, from those parts of the environment that man and his technology have modified and controlled" (NASH, 1976, p. 14). A wilderness seria então um "estado mental", um ambiente não atingido pelo ser humano e suas máquinas. Nash simboliza que existe um outro ambiente, não natural, produzido pela humanidade, em contraponto ao mundo selvagem. O ambiente produzido, no entanto, não atrai o interesse do historiador. O papel da wilderness seria mais importante para uma série de problemas que Nash lista neste mesmo artigo. Fundamentalmente, o autor afirma que os elementos constitutivos desse mundo selvagem seriam importantes para a compreensão da mentalidade moderna, em especial, o interesse das sociedades em preservar a natureza intocada com a criação de parques, tal como Yellowstone e Yosemite nos EUA (NASH, 1976).

Apesar da preocupação de Nash com um tema específico, a wilderness, acabou expressando a orientação teórica que a História Ambiental de matriz ecológica vai utilizar. A

2 Não farei a listagem, exaustiva por sinal, dos pesquisadores brasileiros e suas obras para cada uma das três matrizes propostas. Esse procedimento demandaria um espaço bem maior que o disponível. Isto ficará para outro momento. Em vez disso, aponto pesquisadores nacionais que, no meu entendimento, servem como seus representantes. 
formulação desta perspectiva em questões metodológicas veio por meio de Donald Worster, outro historiador ambiental dos EUA. Para Worster, Nash define ambiente como "paisagem ao redor", em volta do ser humano e da civilização que ele criou. Em um texto de introdução para a Environmental Review de 1987, Worster aponta para este sentido e define a preocupação da História Ambiental:

We are not concerned merely with the history of literary reactions to nature or of conservation policies, as important as those are. We are, in the largest sense, interested in all the ways people organize themselves into patterns of power, production, and ideology in the presence of what we conventionally call nature - the nonhuman world (WORSTER, 1987, p. 251)

O meio ambiente seria encontrado, convencionalmente, no mundo não-humano, portanto, é neste "espaço" que a História Ambiental teria lugar para seus problemas, objetos e análises. Worster, anos depois, no artigo "Para fazer História Ambiental", formaliza essa opção teórica e metodológica e fornece uma definição mais precisa desse meio ambiente. Neste artigo, texto-base da História Ambiental brasileira, ele se refere ao conceito como "mundo não-humano", "ambiente natural", "esfera não-humana". Worster trata de consequências ecológicas, tanto da ação humana quanto a reação natural (suas obras principais refletem esse posicionamento - Dust Bowl/1979 e Rivers of Empire/1985). Em suas palavras: "aprofundar o nosso entendimento de como os seres humanos foram, através dos tempos, afetados pelo seu ambiente natural e, inversamente, como eles afetaram esse ambiente e com que resultados" e que "Em termos bem simples, portanto, a História Ambiental trata do papel e do lugar da natureza na vida humana. Há um consenso de que 'natureza' designa o mundo não-humano, o mundo que nós não críamos originalmente" (WORSTER, 1991, p. 201).

A matriz ecológica tem seus representantes no Brasil. José Augusto Drummond, em artigo de 1991, também texto-base da História Ambiental, trata o meio ambiente como uma "região com alguma homogeneidade ou identidade natural", assim como utiliza os sinônimos "recursos naturais" e "ecossistemas". Ele orienta que os limites dos estudos históricos devem ser naturais e não políticos, sendo o meio ambiente permeado pelas atividades humanas. Como aponta Drummond, há "o diálogo sistemático com quase todas as ciências naturais inclusive as aplicadas - pertinentes ao entendimento dos quadros físicos e ecológicos das regiões estudadas" (DRUMMOND, 1991). 
A matriz ecológica tem como proposta o trabalho com um meio ambiente natural, separado das sociedades humanas, mas em permanente contato com elas. Um contato, no entanto, cuja característica principal também ajuda a compreender a matriz. É através do impacto humano sobre essa natureza intocada que o pesquisador tem seu objeto de estudo. Tanto o impacto que causa a degradação do meio ambiente como aquele que o reduz, em termos ecológicos, em áreas bem definidas e protegidas do restante da sociedade.

A historiografia do impacto é, talvez, aquela que pode ser encontrada em maior quantidade em qualquer lista bibliográfica da História Ambiental. As temáticas estudadas, de forma geral, se originam desta identificação da matriz ecológica com a noção de impacto ambiental. A partir desta relação temos as pesquisas sobre o impacto: da agricultura, pecuária e do agronegócio em geral, da domesticação de espécies ou da implantação de novas biotas nos ecossistemas brasileiros, das readequações urbanísticas de cidades e paisagens, da atuação política de certos setores nacionais na criação de parques e reservas, da ciência e tecnologia etc.

A segunda matriz - socioambiental - mantém a ideia de natureza como sinônimo principal de meio ambiente. A diferença consiste em que o significado segue uma proposição econômica, política e cultural de ambiente. Essa proposta tem como palavra-chave "mundo natural". Espécie de termo curinga nesta matriz, mundo natural resolve muitos problemas epistemológicos. É amplo, pode ou não abarcar a humanidade/sociedades humanas, permite problematizar a relação entre sociedade e natureza, pois não cria fronteiras específicas, tal como ecossistemas e mundo não humano. Esta associação parece ter sido uma sugestão encontrada na obra do historiador inglês Keith Thomas: "O homem e o mundo natural" de 1983, em que o autor define sua pesquisa como a compreensão da percepção e classificação pelo ser humano do mundo natural ao seu redor. Segundo Thomas, a relação entre ser humano e mundo natural é implícita, não podendo serem separados em uma análise histórica, pois "é impossível desemaranhar o que as pessoas pensavam no passado sobre as plantas e os animais daquilo que elas pensavam sobre si mesmas" (THOMAS, 2010, p. 20). Embora esta matriz mantenha a separação entre sociedade e natureza, a relação que se estabelece entre meio ambiente, enquanto natureza, e sociedade é diferente daquela encontrada na matriz ecológica. Agora não se trata mais apenas do impacto, mas, antes, das várias formas de interação entre ambas. 
Os trabalhos de Warren Dean e de Paulo $\mathrm{H}$. Martinez estão entre aqueles que expressam esta matriz conceitual. Em "A Ferro e Fogo", Warren Dean, devido a sua origem estadunidense, mantém a conceituação de meio ambiente em termos ecológicos, fruto da ligação que faz de sua pesquisa com um tipo de história florestal, que estaria nas origens da História Ambiental dos EUA. Dean, porém, traz outras tonalidades em sua análise. Na obra, "mundo natural" aparece enquanto uma totalização do meio ambiente: "O mundo natural, simplificado, em desacordo com os desejos humanos, mas em resposta a seus atos, convertese em uma enorme macega cosmopolita de luto" (DEAN, 1996). O autor ultrapassa a questão do impacto e leva a problematização sobre o meio ambiente para as esferas política, econômica e cultural. O ser humano, na obra de Dean, está profundamente inserido na natureza, não apenas como fator de degradação, devido a suas ações, mas em uma simbiose. Uma relação de mão dupla, que faz com que um caracterize o outro. No caso, a Mata Atlântica é fruto daquilo que o ser humano fez dela e a sociedade brasileira é o resultado de suas práticas frente ao mundo natural.

Paulo H. Martinez, no livro História Ambiental no Brasil, compreende o mundo natural em um sentido amplo. Sua proposição metodológica remete a que devem ser realizados tanto estudos históricos dos "desastres e catástrofes ambientais" quanto aqueles que propõem análises das "formações sociais e econômicas e dos 'agravos' que estas desencadeiam no mundo natural" (MARTINEZ, 2006, p. 19). O autor leva em consideração a construção social do meio ambiente, percebendo o "mundo natural” enquanto "uma natureza com face humana". Uma proposta de História Ambiental e do conceito de meio ambiente que vai ao encontro da matriz ecológica, que visualiza os limites entre humanos e não-humanos.

A questão, para Paulo H. Martinez, como exposta no seu livro $(2006$, p. 19) é de que "Uma das peculiaridades mais destacadas da História Ambiental seria, assim, o exame das relações entre os seres humanos e, dentro e a partir delas, a análise das relações que se estabelecem com o mundo natural". Suas bases estão no materialismo histórico, que lhe permitem aplicar o marxismo na História Ambiental e assim inverter a proposição da matriz ecológica, quando não mais se parte da divisão entre sociedade e natureza, mas da compreensão da construção recíproca entre ambas, tendo, no entanto, como centro analítico as relações econômicas e sociais, por serem estas que, em última instância, definem o mundo natural. 
A matriz socioambiental define o meio ambiente enquanto uma relação em diversos níveis entre sociedade e natureza. Economia, política, cultura e afins compõem essa interação, que pode ou não ser clivada pelo impacto ambiental, não sendo isto uma disposição fundamental, mas uma das possíveis consequências da relação. Os pesquisadores da matriz socioambiental partem para o estudo das políticas ambientais, patrimônio ambiental, educação ambiental etc., temas que tem a sociedade como ponto de partida de problematização para atingir o meio ambiente.

A matriz geográfica está presente na História Ambiental entre os historiadores que abordam, de forma geral, uma história regional. A escolha do "geográfica" na definição não implica necessariamente uma filiação dos pesquisadores com as determinações da disciplina Geografia. Representa que, na interpretação de meio ambiente por parte dos historiadores, enquanto natureza, este fica caracterizado como um espaço, um lugar determinado. Uma cidade, vilarejo, um rio, toda uma região ou então certa paisagem são os objetos analisados pelos historiadores desta matriz. Podem ser considerados uma variação da matriz socioambiental, pois a maioria dos estudos que a compõem tem a preocupação de promover a relação entre sociedade e natureza em termos amplos, porém, focalizando um local específico e retirando dele as implicações dessa interação.

Warren Dean poderia ser listado entre aqueles que promoveram esta interpretação de meio ambiente. $\mathrm{O}$ estudo da Mata Atlântica, já citado aqui, demonstra como a matriz geográfica orienta a perspectiva dos pesquisadores. O foco em um determinado espaço, um lugar cuja qualificação não é exatamente determinada por fronteiras físicas reconhecidamente estabelecidas mas enquanto um espaço definido por uma convenção social. O que é uma mata? Uma floresta? Um rio? Uma cidade? Uma paisagem? Certamente podem ter seus significados atribuídos a delimitações cartográficas, muito embora sejam melhores divisadas pelo imaginário da população do entorno ou, no caso da Mata Atlântica, de toda uma nação.

Nesta matriz, por trazer como característica uma história regional, o recurso à historiografia clássica nacional é constante. Aparece, entre os autores desta matriz, o referencial às obras de Caio Prado Júnior, Sérgio Buarque de Holanda, Gilberto Freyre, Capistrano de Abreu, entre outros. A base das interpretações sobre o meio ambiente é 
montada nesta historiografia tanto pela reflexão sobre os argumentos desses autores ou então na crítica a suas abordagens.

As pesquisas de Dora Shellard Corrêa e Janes Jorge representam aqui a matriz geográfica. A recorrência de ambos à historiografia clássica brasileira é constante. Dora Corrêa, em um artigo de 2007, fez a contraposição das obras de Sérgio Buarque de Holanda e de Capistrano de Abreu com o intuito de apontar para uma interpretação historiográfica que leve em conta a paisagem enquanto "dinâmica e humanizada", não servindo apenas como "cenários de fundo, adornos insignificantes de acontecimentos, estruturas e processos e, muito menos, reflexos puros de um espaço físico visualizado" (CORRÊA 2007, p. 11). A leitura desses autores permitiria a análise sob o viés político da paisagem.

Em seu livro de 2013 "Paisagens sobrepostas", Dora Corrêa leva adiante essa proposição de paisagem e seus desdobramentos junto à historiografia nacional. A historiadora relaciona os processos sociais e os impactos do desenvolvimento econômico no estado de São Paulo à sobreposição de paisagens em uma região específica: o núcleo colonial Barão de Antonina, na área conhecida como Mata de Itapeva. Nesse espaço houve, ao longo dos anos que correm do século XVIII até 1930, uma constante transformação da paisagem. Uma sobreposição de representação da paisagem, como sugere o título da obra, saindo de um sertão no XIX para um aldeamento indígena no início do XX e finalmente um núcleo colonial a partir de 1930. Essas camadas criadas ocultaram as diversas representações do lugar e revelam os sentidos político e jurídico dados a ele a partir de novas concepções advindas de cima, do Estado e sua agenda governamental (CORRÊA, 2013).

Para Janes Jorge, os historiadores brasileiros clássicos trazem vislumbres da relação entre sociedade e natureza. Devido à proximidade entre os dois elementos na história do país, os trabalhos de Caio Prado Júnior, "Formação do Brasil Contemporâneo" e "São Paulo, história e geografia", e, novamente, de Sérgio Buarque de Holanda, "Monções" e "Caminhos e Fronteiras", poderiam, segundo Janes Jorge, serem lidos como "interpretações sobre o modo como sociedade e natureza interagiram em terras brasileiras ao longo do tempo" (JORGE, 2006, p. 19). A historiografia clássica nacional, dessa maneira, fornece o suporte para uma interpretação do meio ambiente na pesquisa deste historiador. No livro "Tietê: o rio que a cidade perdeu", Janes Jorge mostra como a degradação do rio afetou o cotidiano de moradores, ribeirinhos ou então do entorno que ocupavam o lugar e que tinham o rio como 
um espaço de lazer, de trabalho, de transporte etc. Tratando da produção e apropriação do espaço urbano, a transformação do rio Tietê levou também a acentuar a desigualdade social na cidade de São Paulo (JORGE, 2006).

A matriz geográfica, portanto, parte de estudos delimitados espacialmente. Determina um conceito de meio ambiente inserido em uma ótica regional ou a partir de um local de significação social, podendo este ser uma montanha, rio, floresta etc. A ligação com o espaço faz com que os pesquisadores estejam fora da matriz socioambiental e seu afastamento da matriz ecológica vem da preocupação com a análise pautada pela interação entre sociedade e natureza. O meio ambiente neste grupo de historiadores, portanto, pode ser entendido como um conceito plasmado à região, ao local, à paisagem, dependendo da forma como a sociedade se apropria dele.

É importante admitir que as divisões entre as matrizes aqui propostas são extremamente opacas. Isto significa que há uma interlocução entre seus pesquisadores, seus objetos e os métodos de pesquisa. O recurso a enquadrar o conceito de meio ambiente da História Ambiental em determinadas matrizes serve para mais bem entender o ponto de partida dos historiadores envolvidos nesta área da historiografia.

De qualquer maneira, o significado de meio ambiente pela História Ambiental é multifacetado. Está atrelado à problematização da pesquisa ou então ao tipo de objeto que está na mira do historiador (áreas florestais e seus vários ramos, agricultura, pecuária, pesca, fronteiras, territórios ou paisagem). O conceito é polissêmico, porém isto não o livra de ser caracterizado como uma caixa-preta. Ele é definido, assim como na eletrônica, pelos inputs e outputs resultantes do trabalho dos historiadores.

\section{Conclusão}

Existe uma grande dificuldade em "encaixar" o meio ambiente nas ciências humanas. Latour indica que o conceito meio ambiente ora é complementar e ora unificador nos estudos desta área. E estaria caracterizada por uma inversão antropológica, que ocorreu no século XX, quando a natureza passa de forte e dominável para fraca e indefesa. Essa inversão é oriunda da mudança epistemológica que ocorreu por volta dos anos 1970, quando o planeta pode ser observado visto como um todo, internalizado e totalizado pelos pesquisadores. Nota-se a singularização do meio ambiente neste processo. Em vez de falarmos meios ambientes, plural, 
devido ao seu grau de especificidades, utilizamos o termo no singular, como se houvesse apenas um ambiente global indiferente (LATOUR et. al., 1998).

Em geral, o entendimento promovido pelos historiadores ambientais mantém a distância entre sociedade e natureza, meio ambiente e ser humano. Seriam dois elementos deslocados que interagem, mas não são reconhecidos como uma mesma entidade. José Augusto Pádua, em artigo para a revista Estudos Avançados de 2010, afirma que os historiadores mantêm uma relação com o meio ambiente que poderia ser caracterizada como flutuante, no sentido literal da palavra, ao se colocarem em uma posição privilegiada para observação, em suas análises do meio ambiente (PÁDUA, 2010).

A partir da compreensão pela noção de caixa-preta, essa relação flutuante seria mais drástica. É a completa separação em relação ao objeto. Ambos apenas interagem quando o ponto de vista é o conflito. Isto, entendido aqui como a constante interação entre ambos, seja pela degradação causada pelas sociedades humanas ao meio ambiente, seja pelo impacto da natureza no meio social. Mesmo a História Ambiental urbana, ramo que está em franca ascensão na História Ambiental, mantém essa separação. O olhar do pesquisador da História Ambiental urbana está focando, em grande parte das pesquisas, os nichos do "mundo natural", "natureza" e afins nas cidades, ou seja, são os rios, parques, praças, árvores, animais etc. Mantém o ser humano no entorno do meio ambiente ou vice-versa. A perspectiva de trabalho com as categorias ambiente natural e ambiente artificial, por exemplo, é pouco ou quase nada utilizado, causando perdas epistemológicas na compreensão do objeto de estudo e da problematização histórica.

A caixa-preta, selada, da forma como está, não permite a discussão do sentido que o pesquisador pretende dar ao meio ambiente. É este sentido que determina os rumos adotados na abordagem historiográfica. Não afirmo aqui a necessidade de a História Ambiental ter uma definição para meio ambiente. Mas precisa-se, ao menos, ultrapassar a dicotomia, que ora está oculta ora declarada nos trabalhos, entre sociedade e natureza. Neste sentido, os pesquisadores dedicados a este ramo contribuiriam significativamente com as demais ciências trazendo à luz a historicidade de meio ambiente e o arcabouço interpretativo da historiografia sobre o tema.

\section{REFERÊNCIAS}


ALMEIDA, Jozimar Paes de. Questões conceituais na História Ambiental. In: GIANNATASIO, Gabriel; IVANO, Rogério. (Orgs.). Epistemologias da história: verdade, linguagem, realidade, interpretação e sentido na pós-modernidade. Londrina: EDUEL, 2011.

CORRÊA, Dora Shellard. Descrição da paisagem no trabalho historiográfico. Diálogos entre Capistrano de Abreu e Sérgio Buarque de Holanda. Maquinações, v. 1, n. 1, p. 10-11, 2007

. Paisagens sobrepostas:índios, posseiros e fazendeiros nas matas de Itapeva (1723-1930). Londrina: EDUEL, 2013.

D’AGOSTINI, Luiz Renato. A insuficiência do conceito de meio ambiente em meios onde o meio é ambiente. Geosul, v. 17, n. 34, p. 147-154, 2002.

DEAN, Warren. A ferro e fogo: a história e a devastação da Mata Atlântica brasileira. São Paulo: Companhia das Letras, 1996.

DRUMMOND, José Augusto. A História Ambiental: temas, fontes e linhas de pesquisa. Estudos Históricos, v. 4, n. 8, p. 177-197, 1991.

HOLZER, Werther. Uma discussão fenomenológica sobre os conceitos de paisagem e lugar, território e meio ambiente. Revista Território, v. 2, n. 3, p. 77-85, 1997.

JORGE, Janes. Tietê: o rio que a cidade perdeu. São Paulo (1890-1940). São Paulo: Alameda, 2006.

LATOUR, Bruno. Ciência em ação: como seguir cientistas e engenheiros sociedade afora. São Paulo: Editora UNESP, 2000.

LATOUR, Bruno, Schwartz, Cécile y Chavolin, Florian. Crises dos meios ambientes: desafios às ciências humanas. In: ARAÚJO, Hermetes Reis de. (Org.). Tecnociência e cultura: ensaios sobre o tempo presente. São Paulo: Estação Liberdade, 1998.

MARTINEZ, Paulo Henrique. História Ambiental no Brasil: pesquisa e ensino. São Paulo: Cortez, 2006.

NASH, Roderick. The value of wilderness. Environmental Review, v. 1, n. 3, p. 12-25, 1976.

ODUM, Eugene. Fundamentos da ecologia. 6a Ed. Lisboa: Fundação Calouste Gulbenkian, 2004.

OLIVEIRA. Manoel Carlos de. Discussões sobre o conceito de meio ambiente. Revista IG, v. 3, n 2, p. 53-60, 1982.

PÁDUA, José Augusto. As bases teóricas da História Ambiental. Estudos Avançados, v. 24, n. 68, p. 81$101,2010$.

PINCH, Trevor J.; BIJKER, Wiebe E. The social construction of facts and artifacts: or how the sociology of science and the sociology of technology might benefit each other. Social Studies of Science, v. 14, n. 3, p. 399-441, 1984.

RIBEIRO, Wagner Costa. Meio ambiente: o natural e o produzido. Revista Departamento de Geografia USP/FFLCH, n.5, p. 29-32, 1991.

THOMAS, Keith. $O$ homem e o mundo natural: mudanças de atitude em relação às plantas e aos animais (1500-1800). São Paulo: Companhia das Letras, 2010. 
WORSTER, Donald. Dust Bowl: the southern plains in the 1930s. New York: Oxford University Press, 2004.

Para fazer História Ambiental. Estudos Históricos, v. 4, n. 8, p. 198-215, 1991.

Rivers of Empire: water, aridity, and the growth of the American West. New York: Oxford University Press, 1985. 